\title{
CrystEngComm
}

Check for updates

Cite this: CrystEngComm, 2021, 23, 700

Received 4th October 2020 ,

Accepted 1st December 2020

DOI: 10.1039/d0ce01454k

rsc.li/crystengcomm

\section{Crystallisation studies of sodium acetate trihydrate - suppression of incongruent melting and sub-cooling to produce a reliable, high- performance phase-change material $\dagger$}

\author{
David E. Oliver, ${ }^{\text {ab }}$ Andrew J. Bissell, ${ }^{\text {b Xiaojiao Liu, (D) }}{ }^{\text {a }}$ \\ Chiu C. Tang ${ }^{c}$ and Colin R. Pulham (D) *a
}

\begin{abstract}
This study has identified two polymer additives that when added in low concentrations can be used to reliably prevent incongruent melting of sodium acetate trihydrate (SAT) when temperature-cycled over multiple thousands of melting and freezing cycles. The polymers appear to act as crystal-habit modifiers that at sub-optimal concentrations dramatically alter the morphology of any anhydrous sodium acetate that may be formed, and at higher concentrations completely suppress precipitation of anhydrous sodium acetate. In situ X-ray powder diffraction experiments show that the active nucleator for SAT is $\mathrm{Na}_{2}{ }^{-}$ $\mathrm{HPO}_{4} \cdot 2 \mathrm{H}_{2} \mathrm{O}$, and that the mechanism of thermally induced deactivation is dehydration in solution to form anhydrous $\mathrm{Na}_{2} \mathrm{HPO}_{4}$. Based on these studies, new formulations of SAT have been developed that demonstrate consistent and reliable performance as phase-change materials for heat-storage applications.
\end{abstract}

\section{Introduction}

With the growth in renewable energy sources and the requirement to reduce $\mathrm{CO}_{2}$ emissions, there is an increasing requirement for technologies that store heat or cold for both domestic and industrial applications. Phase-change materials (PCMs) represent an important class of materials that offer potential for heat storage, absorbing heat on melting and releasing heat on freezing. ${ }^{1}$ Applications for PCMs include: domestic water and space heating; solar thermal storage; refrigeration; and air-conditioning. PCMs include: organic compounds such as paraffins, long-chain fatty acids and esters, sugar alcohols (e.g. erythritol); low-melting metal alloys; and salt hydrates. ${ }^{1-3}$ In order to retain long-term stability and reproducible performance, heat-storage systems that use PCMs are required to undergo multiple melting and freezing cycles without any change in melting point and heat output. Salt hydrates are attractive candidates on account of their high energy densities and low-flammability, but there remain issues associated with their long-term stabilities and reliable nucleation. This is exemplified by sodium acetate

${ }^{a}$ EaStCHEM School of Chemistry, The University of Edinburgh, Joseph Black Building, David Brewster Road, Edinburgh, EH9 3FJ, Scotland, UK.

E-mail:C.R.Pulham@ed.ac.uk

${ }^{b}$ Sunamp Ltd., Macmerry Business Park, 1 Satellite Park, Tranent, EH33 1RY, Scotland, UK

${ }^{c}$ Diamond Light Source, Diamond House, Harwell Science and Innovation Campus, Fermi Ave, Didcot OX11 ODE, UK

$\dagger$ Electronic supplementary information (ESI) available. See DOI: 10.1039/d0ce01454k trihydrate (SAT), which has a high energy density (values in the range $226-260 \mathrm{~kJ} \mathrm{~kg}^{-1}$ have been reported), a melting point of $58{ }^{\circ} \mathrm{C}$ (ideal for delivery of domestic hot water), is non-toxic, and has a very low flammability. ${ }^{3-6}$ However, SAT suffers from two significant disadvantages that have until now restricted its widespread use as a reliable PCM. The first is incongruent melting whereby instead of melting to form a homogenous solution (melt) of trihydrate, phase segregation occurs and anhydrous sodium acetate precipitates from solution. ${ }^{4,5}$ This is illustrated in the phase diagram (Fig. 1).

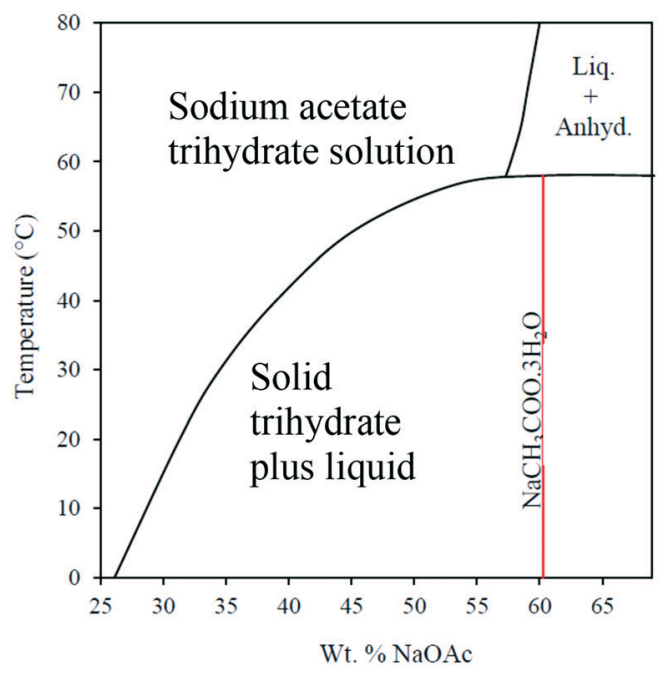

Fig. 1 Phase diagram for sodium acetate and water, modified from ref. 5. 
This reflects the fact that at $58{ }^{\circ} \mathrm{C}$ the solubility limit of sodium acetate in water is $58.0 \mathrm{wt} \%(138.10 \mathrm{~g} / 100 \mathrm{ml})$, whereas sodium acetate trihydrate corresponds to a composition of $60.28 \mathrm{wt} \%$ sodium acetate $(151.76 \mathrm{~g} / 100 \mathrm{ml})$, i.e. a significantly higher concentration than the solubility limit of sodium acetate at $58{ }^{\circ} \mathrm{C}$. One potentially simple solution to this problem is to add extra water in order to form a $58 \mathrm{wt} \%$ composition that is fully liquid at $58{ }^{\circ} \mathrm{C}$. This should produce a thermodynamically stable solution at 58 ${ }^{\circ} \mathrm{C}$, i.e. it is neither in the metastable zone nor in the supersaturated zone and thus no solid should precipitate. Nevertheless, it has been observed that temperature cycling of 58 wt $\%$ composition did still precipitate anhydrous sodium acetate and even when a $56 \mathrm{wt} \%$ composition was cycled 100 times, extensive precipitation of the anhydrous salt was observed. ${ }^{7}$ Moreover, dilution from the ideal trihydrate composition substantially lowers the freezing temperature and reduces the energy density of the PCM. ${ }^{7}$ Previous attempts to overcome the incongruent melting of SAT have exploited the use of thickening agents to prevent the precipitation and settling of anhydrous sodium acetate. For example, Cabeza et al. explored the use of starch, bentonite, methylhydroxyethyl-cellulose and methylcellulose. $^{8}$ Of these, the most promising was methylhydroxyethyl-cellulose at a loading of $30 \mathrm{wt} \%$, but this decomposed if heated to above $65{ }^{\circ} \mathrm{C}$. Such high loadings also resulted in a reduction in the latent heat of fusion by up to $35 \% .{ }^{8}$ Wada et al. studied polyvinyl alcohol as a thickener, combined with paraffin oil $(1 \%)$, acetone $(0.5 \%)$ and extra water $(3.5 \%) .{ }^{9}$ They found that the stability of the sample was greatly improved compared to pure SAT. However, variability in the measured value of the latent heat of fusion was still observed, although this aspect was not elaborated on further. More recently Kong et al. have described the use of mixtures of SAT containing carboxy-methyl cellulose, xanthan gum, and unspecified polymers to prevent sub-cooled SAT from precipitating on standing at ambient temperature for extended periods of time. ${ }^{10}$ These formulations indicated that the energy storage density was retained when compared to samples of pure SAT suffering from phase separation. However, the formulations were not subjected to thermal cycling. Liu et al. have reported a formulation based on SAT adsorbed in micro-porous, expanded vermiculite. ${ }^{11}$ Thermogravimetric results showed that the phase separation problems were almost overcome, and thermal cycling showed that the composite PCM was stable over 150 meltingsolidification cycles. The performance improvement of SAT was attributed to the micro-scale phase change and heat transfer within the pores of the expanded vermiculite. ${ }^{11}$

The second disadvantage of SAT is its strong tendency to sub-cool (super-cool) well below its normal freezing point. Sub-cooling is a consequence of the failure to nucleate crystallisation of the liquid and is a common phenomenon displayed by many salt hydrates. Whilst sub-cooling can be exploited in devices such as disc-activated hand-warming packs, this is a major disadvantage for other applications which require reliable and reproducible freezing of the PCM. Mechanically induced nucleation can be achieved for handwarming packs through the use of a small metal disc that, when flexed, releases into the liquid tiny seed crystallites that induce nucleation and subsequent crystallisation. ${ }^{12}$ Seed crystallites are trapped within sub-micron cracks on the surface of the disc and persist even at regeneration temperatures of $100{ }^{\circ} \mathrm{C}$. Nucleation of SAT may also be induced by the addition of additives that include: silicon carbide and bentonite, ${ }^{13}$ expanded graphite, ${ }^{14}$ copper nanoparticles, ${ }^{15}$ and chitin nano-whiskers. ${ }^{16}$ Perhaps the most well-studied and reliable nucleators that have been reported are based on disodium hydrogenphosphate $\left(\mathrm{Na}_{2} \mathrm{HPO}_{4}, \mathrm{Na}_{2}\right.$ $\left.\mathrm{HPO}_{4} \cdot 7 \mathrm{H}_{2} \mathrm{O}, \quad \mathrm{Na}_{2} \mathrm{HPO}_{4} \cdot 12 \mathrm{H}_{2} \mathrm{O}\right)^{8,17,18}$ and tetrasodium pyrophosphate $\left(\mathrm{Na}_{4} \mathrm{P}_{2} \mathrm{O}_{7}\right.$ and $\left.\mathrm{Na}_{4} \mathrm{P}_{2} \mathrm{O}_{7} \cdot 10 \mathrm{H}_{2} \mathrm{O}\right) \cdot{ }^{19}$ However, there are widespread reports about the 'deactivation' of these nucleators, i.e. under certain conditions they no longer nucleate SAT when cooled below its melting point. ${ }^{20-24}$ In particular, when the temperature of samples of SAT containing these nucleators exceeds $80{ }^{\circ} \mathrm{C}$, then nucleation on subsequent cooling becomes sporadic, and when samples are heated above $90^{\circ} \mathrm{C}$, then deactivation of the nucleator is complete and subsequent nucleation fails completely. One explanation that has been presented for this deactivation of the nucleator is that seed crystals of SAT are adsorbed on the surface of the nucleator and persist some way above the melting point of SAT, but at higher temperatures these seed crystals desorb from the surface and then immediately melt. $^{22}$ However, no experimental evidence has been provided to corroborate this hypothesis.

The twin challenges of incongruent melting of SAT and deactivation of the nucleator continue to severely restrict the use of SAT in heat-storage systems where reproducible performance over multiple thousands of heating/cooling cycles and long-term stability is crucial. The purpose of this study was therefore to identify a reliable method to prevent the incongruent melting of SAT and to investigate the mechanism of deactivation of hydrogenphosphate-based nucleators.

\section{Result and discussion}

\section{Incongruent melting studies}

Although polymers have been used to increase the viscosity of SAT solutions thereby leading to the suspension of anhydrous sodium acetate, our approach was instead to investigate polymer additives that directly inhibit the nucleation and/or growth of crystallites of anhydrous sodium acetate. The use of additives to modify crystallisation processes is widely practised across a range of sectors including pharmaceuticals, bio-fuels, food processing, and the oil industry. One extensively studied system is the crystallisation of barium sulfate in the presence of soluble phosphonate-based polymers. The nucleation and growth of insoluble barium sulfate can be inhibited by the addition of polymer additives, which also act as crystal-habit modifiers. ${ }^{25}$ 
There were several key requirements for the selection of polymers that might prevent incongruent melting of SAT. The primary consideration was solubility, especially as hydrocarbonbased polymers are often only poorly soluble in aqueous solutions on account of their hydrophobic backbone. In recognition that the measured $\mathrm{pH}$ of molten $\mathrm{SAT}$ is $\sim 10$ and that there is a very high concentration of sodium ions, studies focused on poly-carboxylates, poly-carboxylic acids, poly-amines, poly-alcohols, and poly-ethers. For commercial applications, additional requirements include the following: readily available, non-hazardous, low-cost, and sufficiently low viscosity to enable easy pouring. Initial screening studies investigated the effects on incongruent melting for 55-58 wt\% aqueous solutions of sodium acetate with polymers added over the range 1-5 wt $\%$. Samples were repeatedly thermally cycled between $20-60{ }^{\circ} \mathrm{C}$, with crystallisation of the sub-cooled solution initiated by the addition of a crystallite of SAT. The appearance of anhydrous sodium acetate in the melt was monitored visually, and if precipitation occurred then the sample was heated to $75^{\circ} \mathrm{C}$ with stirring to re-dissolve the solid. An additional test investigated whether any anhydrous sodium acetate precipitated from a subcooled solution on standing for 24 hours at $20{ }^{\circ} \mathrm{C}$. From these studies, two polymer systems showed promising performance: a $1: 2$ copolymer of methacrylic acid and methyl methacrylate $\left(M_{\mathrm{w}}\right.$ in range 500 000-1 000000 ), shown in Fig. 2; a $30 \mathrm{wt} \%$ aqueous solution of the sodium salt of poly(methacrylic acid) $M_{\mathrm{w}} \sim 9500$ by GPC, 30 wt $\%$ in $\mathrm{H}_{2} \mathrm{O}$, or alternatively, poly(methacrylic acid, sodium salt) solution average $M_{\mathrm{w}} 4000-6000,40 \mathrm{wt} \%$ in $\mathrm{H}_{2} \mathrm{O}$-see Fig. 2.

At loadings of $1 \mathrm{wt} \%$ these polymers were readily soluble in molten SAT and consistently prevented precipitation of anhydrous sodium acetate from a $58 \mathrm{wt} \%$ aqueous solution from both the hot and sub-cooled melts over multiple $(>40)$ heating and cooling cycles. In order to optimise these formulations, experiments were then conducted to establish the upper concentration limit of the sodium acetate solution with a 1 wt\% loading of polymer that would not melt incongruently. The limit was found to be $58.24 \mathrm{wt} \%$ sodium acetate to $41.76 \mathrm{wt} \%$ water, which is in close agreement with the limiting ratio derived from the previously reported phase diagram shown in Fig. 1. ${ }^{5}$ This corresponds to a slightly water-rich composition $\mathrm{NaCH}_{3} \mathrm{CO}_{2} \cdot\left(\mathrm{H}_{2} \mathrm{O}\right)_{3.35}$ compared to

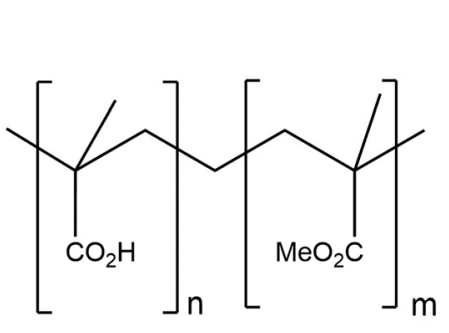

(a)

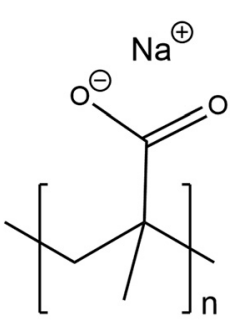

(b)
Fig. 2 Structures of (a) poly(methacrylic acid-co-methyl methacrylate) (PMMA-Co-MAA - ratio $n: m \quad 1: 2$ ) and (b) sodium salt of poly(methacrylic acid) (Na-PMAA).
SAT. Similar optimisation experiments were conducted to obtain lower limits for the concentrations of polymers required to prevent incongruent melting. These results are summarised in Tables 1 and 2.

Differential scanning calorimetry (DSC) measurements (at heating rates of $10{ }^{\circ} \mathrm{C} \mathrm{min}^{-1}$ ) were conducted to ascertain the effect of the polymer additives and additional water on both the melting points and the latent heat of these formulations. Consistent melting points of $58{ }^{\circ} \mathrm{C}$ and enthalpies of fusion of $218 \mathrm{~kJ} \mathrm{~kg}^{-1}$ (278 kJ dm${ }^{-3}$ ) were obtained (see ESI $\dagger$ ), thereby demonstrating that these compositions retain acceptably high energy densities.

When experiments were conducted using a sub-optimal amount $(0.5 \mathrm{wt} \%)$ of the Na-PMAA polymer and on standing for a period of two weeks in a sub-cooled state at $20{ }^{\circ} \mathrm{C}$, precipitation of a mass of extremely thin needles was observed (Fig. 3a). Despite the effects of strong preferred orientation, the powder X-ray diffraction pattern identified this material as anhydrous sodium acetate. ${ }^{26}$ However, the observed crystal morphology was very different from the much larger, plateshaped crystals of anhydrous sodium acetate that crystallise from an aqueous solution in the absence of the polymer (see Fig. 3b). This indicates that the polymer is acting as a crystalhabit modifier that dramatically changes the morphology of anhydrous sodium acetate crystallites. Moreover, it was observed that these needle-shaped crystals rapidly dissolved on heating the solution to $60{ }^{\circ} \mathrm{C}$, and much more readily than the plate-like crystals formed in the absence of the polymer. This presumably reflects the much larger surface area-to-volume ratio of the needles. Hence it appears that at high concentrations the polymer inhibits formation of anhydrous sodium acetate, and at lower concentrations it modifies the morphology of any anhydrous sodium acetate formed such that it readily dissolves on heating.

Both polymers displayed a striking ability to inhibit nucleation of anhydrous sodium acetate. However, it is clear from these experiments that chain length, molecular weight, and viscosity are not dominant factors the suppression mechanism, i.e. PMMA-co-MAA has a much longer chain length and molecular weight than Na-PMAA, and results in a much more viscous solution than Na-PMAA. Moreover, other highly viscous samples failed to prevent incongruent melting e.g. poly(acrylamide) with $M_{\mathrm{w}}=5-6000000$.

At present, the mechanism of action of the two polymers is not known. We can speculate that at a $\mathrm{pH}$ of 10 , both polymers contain carboxylate groups that could bind strongly with sodium ions associated either with pre-nucleation

Table 1 Final composition mass percentages for SAT with PMMA-coMAA

\begin{tabular}{lc} 
Final composition & Weight percentage \\
\hline PMMA-co-MAA & $0.80 \%$ \\
Sodium acetate & $57.78 \%$ \\
Water & $41.42 \%$
\end{tabular}

Weight ratio of sodium acetate to water $=0.5824: 0.4176$ 
Table 2 Final composition mass percentages for SAT with Na-PMAA

\begin{tabular}{lc}
\hline Final composition & Weight percentage \\
\hline Na-PMAA & $0.67 \%$ \\
Sodium acetate & $57.85 \%$ \\
Water & $41.48 \%$
\end{tabular}

Weight ratio of sodium acetate to water $=0.5824: 0.4176$

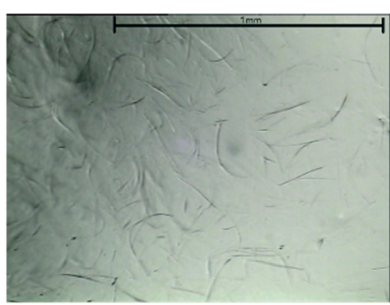

(a)

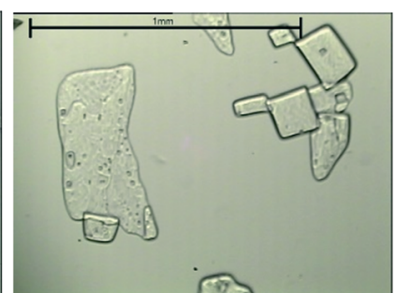

(b)
Fig. 3 Anhydrous sodium acetate crystals grown from an aqueous sodium acetate (58.24 wt\%) sub-cooled solution: (a) in the presence of $\mathrm{Na}-\mathrm{PMAA}$ polymer and (b) in the absence of polymer (scale bar represents $1 \mathrm{~mm}$ ).

clusters or with particular surfaces of small crystallites. The hydrophobic alkyl chains would then prevent further attachment of other ions to these clusters or to particular crystal faces. However, this remains conjecture at this stage.

\section{Nucleation studies}

The effects of anhydrous $\mathrm{Na}_{2} \mathrm{HPO}_{4}, \quad \mathrm{Na}_{2} \mathrm{HPO}_{4} \cdot 7 \mathrm{H}_{2} \mathrm{O}$, anhydrous $\mathrm{Na}_{4} \mathrm{P}_{2} \mathrm{O}_{7}$, and $\mathrm{Na}_{4} \mathrm{P}_{2} \mathrm{O}_{7} \cdot 10 \mathrm{H}_{2} \mathrm{O}$ on the nucleation of SAT were studied by adding up to $1-5 \mathrm{wt} \%$ of the nucleator (in the form of a lightly ground, polycrystalline powder) to 25 $\mathrm{ml}$ of a PCM composition containing Na-PMAA as described above. In agreement with previous studies, it was found that all were effective at reliably initiating the crystallisation of SAT at or very close to $58{ }^{\circ} \mathrm{C}$ (see ESI $†$ ). In view of the potential for the two hydrates to change their hydration state depending on environmental conditions, we chose to focus only on the anhydrous compounds. It was found that the solubilities of $\mathrm{Na}_{2} \mathrm{HPO}_{4}$ and $\mathrm{Na}_{4} \mathrm{P}_{2} \mathrm{O}_{7}$ in molten SAT were $\sim 0.4 \mathrm{wt} \%$ and $\sim 0.15 \mathrm{wt} \%$, respectively. On cycling the samples of SAT containing either $\mathrm{Na}_{2} \mathrm{HPO}_{4}$ or $\mathrm{Na}_{4} \mathrm{P}_{2} \mathrm{O}_{7}$ for variable time periods at temperatures above $70{ }^{\circ} \mathrm{C}$, it was observed that nucleation was no longer reliable. However, no systematic patterns were discerned other than that deactivation was dependent not only on temperature, but also on the time held at elevated temperature and the quantity of nucleator added. In general, the longer the time held at elevated temperatures the more likely it was that the nucleator became deactivated. Smaller quantities of added nucleator resulted in more rapid deactivation after only a few cycles. When heated over the temperature range $79-87^{\circ} \mathrm{C}$, samples nucleated inconsistently on cooling, and always failed to nucleate when heated above $87{ }^{\circ} \mathrm{C}$. These observations are consistent with previous studies ${ }^{20-24}$ and demonstrate that the use of Na-PMAA to prevent incongruent melting does not prevent deactivation of these two phosphate-based nucleator. Very similar results were obtained when PMMA-co-MAA [poly(methacrylic acid-comethyl methacrylate)] was used as the polymer. We also noticed that it was possible to reactivate the behaviour of the nucleator, either by reducing the temperature of sub-cooled samples to below $0{ }^{\circ} \mathrm{C}$ or adding a seed crystal of SAT in order to promote crystallisation of the entire sample. Subsequent warming and cooling cycles that did not exceed $70{ }^{\circ} \mathrm{C}$ resulted in reproducible crystallisation at $58{ }^{\circ} \mathrm{C}$.

In order to gain further insight into the thermally induced mechanism for the deactivation of $\mathrm{Na}_{2} \mathrm{HPO}_{4}$, we conducted in situ, variable temperature powder X-ray diffraction experiments using Beamline I11 at the Diamond Light Source, UK. ${ }^{27,28}$ This high-intensity synchrotron source, combined with this beamline's high-resolution capability and sensitive detectors, allowed complete diffraction patterns from weakly scattering samples in thin-walled capillaries to be recorded with a scan time of 2 seconds. Samples were prepared by dissolving anhydrous sodium acetate in deionised water in a glass vial with addition of PMMA-coMAA and a small quantity of anhydrous $\mathrm{Na}_{2} \mathrm{HPO}_{4}$ (see Experimental details for full procedure $\$$ ).

Fig. 4(a)-(e) show the sequence of X-ray powder diffraction patterns of SAT and nucleator recorded under different conditions. Fig. 4(a) shows the pattern obtained for the initial loading of the capillary at $25{ }^{\circ} \mathrm{C}$, and two polycrystalline components can readily be identified by comparison with reference patterns: namely SAT and $\mathrm{Na}_{2} \mathrm{HPO}_{4}$. Fig. 5 shows the experimental pattern for the initial loading fitted with a Rietveld refinement to SAT and $\mathrm{Na}_{2} \mathrm{HPO}_{4} \cdot 2 \mathrm{H}_{2} \mathrm{O}$, using as starting points the crystal structures of SAT (CSD identifier code NAACET01) ${ }^{29}$ and $\mathrm{Na}_{2} \mathrm{HPO}_{4} \cdot 2 \mathrm{H}_{2} \mathrm{O}$ (ICSD collection code 1289). ${ }^{30}$ All of the Bragg peaks in the experimental pattern

$\ddagger$ Experimental details for the in situ X-ray powder diffraction studies: $8.1896 \mathrm{~g}$ of anhydrous sodium acetate was added to $5.9427 \mathrm{~g}$ of deionised water, together with $0.1213 \mathrm{~g}$ poly(methacrylic acid-co-methyl methacrylate) and $0.2824 \mathrm{~g}$ of anhydrous $\mathrm{Na}_{2} \mathrm{HPO}_{4}$ in a glass vial. The sample was heated to $70{ }^{\circ} \mathrm{C}$ with occasional shaking to dissolve any remaining SAT. The sample was then cycled repeatedly ( $>8$ times) between $20^{\circ} \mathrm{C}$ and $65^{\circ} \mathrm{C}$, and maintained at the highest temperature in order to ensure complete dissolution of any seed crystals of SAT. Congruent melting was observed on heating and spontaneous crystallisation was observed on cooling to $58{ }^{\circ} \mathrm{C}$. Initial attempts to load a $0.7 \mathrm{~mm}$ diameter borosilicate capillary directly from the liquid melt (using capillary action) were unsuccessful - no crystallites of $\mathrm{Na}_{2} \mathrm{HPO}_{4}$ could be detected in the capillary. Instead the sample was heated to $65^{\circ} \mathrm{C}$, vigorously shaken and then allowed to settle for 10 seconds. Half of the liquid sample was then decanted off and the remainder was then shaken. A small aliquot was poured into a chilled mortar, where crystallisation occurred immediately. The sample was ground to a fine powder with a pestle and mortar, and then loaded into a $0.7 \mathrm{~mm}$ capillary. The open end of the capillary was then sealed with superglue adhesive and mounted on the diffractometer operating with a wavelength of $0.82694 \AA$. The capillary was rotated at $360 \mathrm{rpm}$ in order to achieve acceptable powder averaging, and the temperature was controlled using an Oxford Cryosystems Cryostream. Using the PSD Mythen detector, it was possible to collect high-quality patterns with scan times of $2 \mathrm{~s}$. 


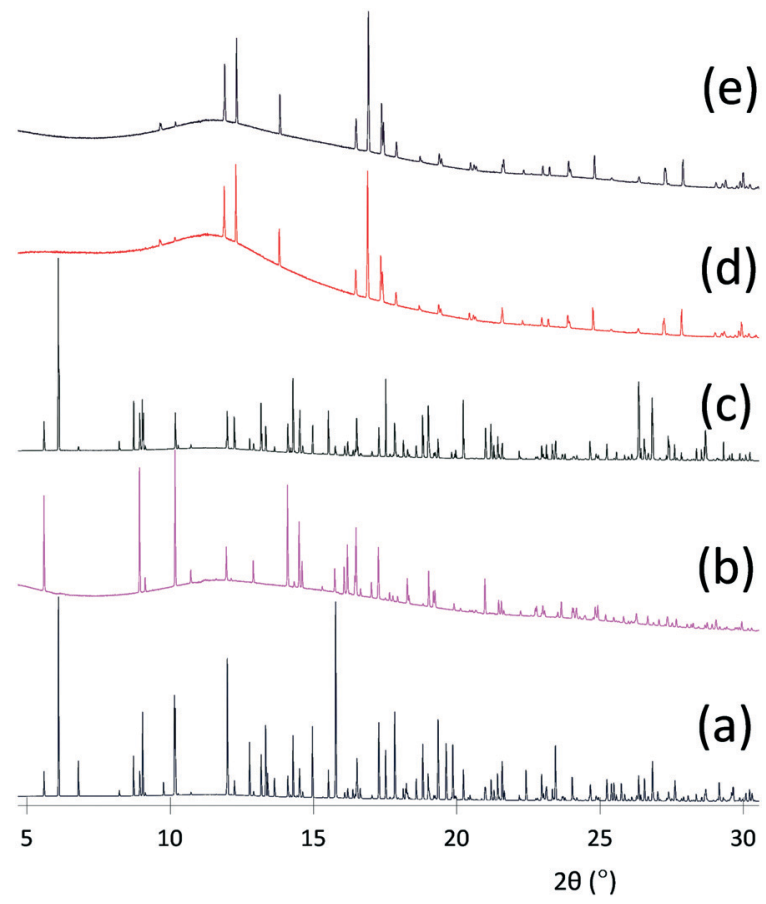

Fig. 4 Sequence of X-ray powder diffraction patterns of SAT and nucleator recorded under different conditions: (a) initial loading of capillary at $25^{\circ} \mathrm{C}$; (b) sample warmed to $62{ }^{\circ} \mathrm{C}$; (c) sample cooled to 25 ${ }^{\circ} \mathrm{C}$; (d) sample warmed to $90^{\circ} \mathrm{C}$; (e) sub-cooled sample at $25^{\circ} \mathrm{C}$.

can be fitted to a mixture of SAT and $\mathrm{Na}_{2} \mathrm{HPO}_{4} \cdot 2 \mathrm{H}_{2} \mathrm{O}$, and no signs of anhydrous $\mathrm{Na}_{2} \mathrm{HPO}_{4}$ or any of the other known hydrates $\left[\mathrm{Na}_{2} \mathrm{HPO}_{4} \cdot 7 \mathrm{H}_{2} \mathrm{O}, \mathrm{Na}_{2} \mathrm{HPO}_{4} \cdot 12 \mathrm{H}_{2} \mathrm{O}\right]$ were detected.

Fig. 4(b) shows the pattern obtained on initially warming to $62{ }^{\circ} \mathrm{C}$. All of the SAT melted and this contributes to the amorphous background observed in the pattern. The remaining Bragg peaks originate entirely from the $\mathrm{Na}_{2}$ -

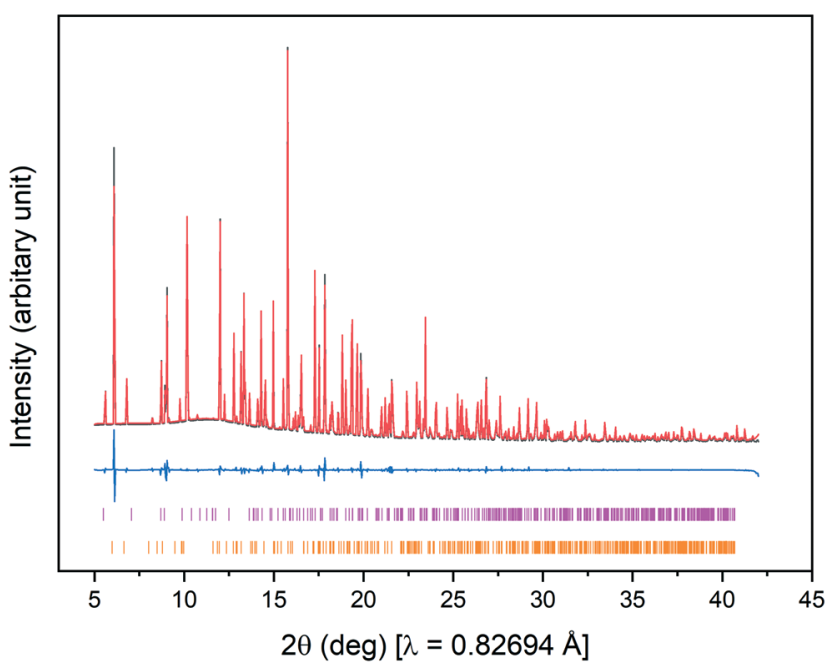

Fig. 5 Rietveld refinement (black - experimental; red - calculated; and blue - difference) of the experimental X-ray powder diffraction pattern for the initial loading of the capillary at $25{ }^{\circ} \mathrm{C}$ showing the presence of both SAT (orange tick marks) and $\mathrm{Na}_{2} \mathrm{HPO}_{4} \cdot 2 \mathrm{H}_{2} \mathrm{O}$ (pink tick marks), with phase fractions of $90.3 \%$ and $9.7 \%$, respectively.
$\mathrm{HPO}_{4} \cdot 2 \mathrm{H}_{2} \mathrm{O}$ that remained suspended in the liquid. On cooling the sample, crystallisation of SAT occurred with no appreciable sub-cooling. Fig. 4(c) shows the pattern recorded at $25{ }^{\circ} \mathrm{C}$ and although inevitably there is a high degree of preferred orientation caused by crystallisation of SAT within the capillary, all of the peaks can be assigned to a mixture of SAT and $\mathrm{Na}_{2} \mathrm{HPO}_{4} \cdot 2 \mathrm{H}_{2} \mathrm{O}$.

Fig. 4(d) shows the pattern recorded when the sample was subsequently warmed to $90{ }^{\circ} \mathrm{C}$. Again, all of the SAT melted, but on this occasion, peaks from $\mathrm{Na}_{2} \mathrm{HPO}_{4} \cdot 2 \mathrm{H}_{2} \mathrm{O}$ disappeared and were replaced with a new set of peaks that can be assigned to anhydrous $\mathrm{Na}_{2} \mathrm{HPO}_{4}$, by comparison with the reference pattern simulated from the crystal structure of $\mathrm{Na}_{2}$ $\mathrm{HPO}_{4}$ (ICSD collection code 81304). ${ }^{31}$ Fig. 6 shows this in more detail - Rietveld refinement of the pattern recorded at $90{ }^{\circ} \mathrm{C}$ shows that anhydrous $\mathrm{Na}_{2} \mathrm{HPO}_{4}$ is the only polycrystalline phase present. On cooling to $25{ }^{\circ} \mathrm{C}$, Fig. $4(\mathrm{e})$ shows that SAT failed to crystallise and that anhydrous $\mathrm{Na}_{2}$ $\mathrm{HPO}_{4}$ persisted. Hence it appears that heating to $90{ }^{\circ} \mathrm{C}$ results in thermally induced dehydration of the dihydrate to form the anhydrous form, which persists on cooling to $25^{\circ} \mathrm{C}$ (see $\mathrm{ESI} \dagger$ for corresponding Rietveld refinement), and that the anhydrous form fails to prevent sub-cooling of SAT.

This set of in situ experiments therefore shows that the active nucleator for SAT is actually the dihydrate, $\mathrm{Na}_{2}$ $\mathrm{HPO}_{4} \cdot 2 \mathrm{H}_{2} \mathrm{O}$, and that the mechanism of thermally induced deactivation is dehydration in solution to form anhydrous $\mathrm{Na}_{2} \mathrm{HPO}_{4}$. Hence, this provides an explanation for the observation in bulk samples that deactivation of the nucleator was dependent not only on temperature, but also on the time held at elevated temperature and the quantity of nucleator added. Further support for this dehydration mechanism is provided by the results of a combined TGA/ Raman study that mapped the sequential thermally induced dehydration of $\mathrm{Na}_{2} \mathrm{HPO}_{4} \cdot 12 \mathrm{H}_{2} \mathrm{O}$ in the solid phase. ${ }^{32}$ Five

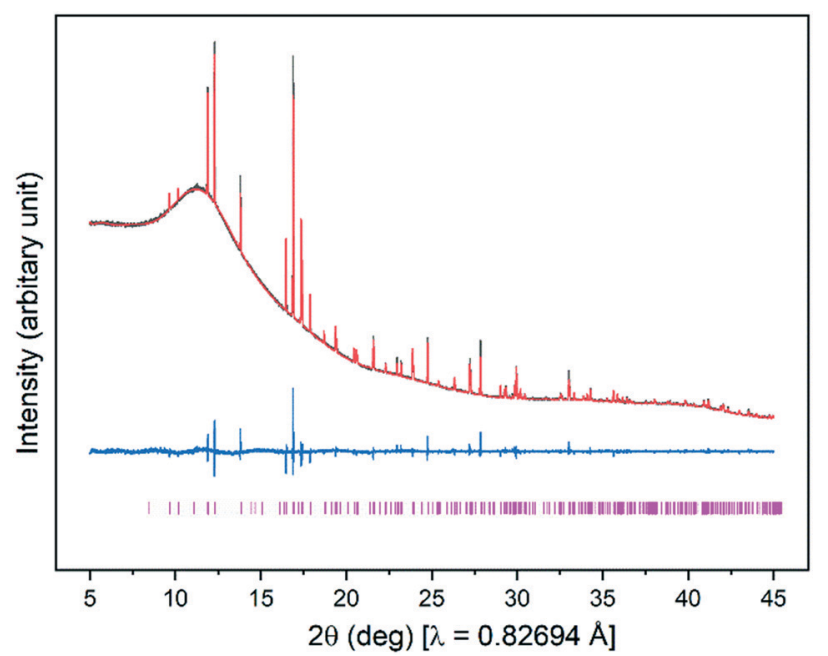

Fig. 6 Rietveld refinement (black - experimental; red - calculated; and blue - difference) of the experimental X-ray powder diffraction pattern of the liquid sample at $90{ }^{\circ} \mathrm{C}$ showing the presence of anhydrous $\mathrm{Na}_{2}-$ $\mathrm{HPO}_{4}$ (pink tick marks). 
Table 3 Composition of optimum PCM formulation

\begin{tabular}{lc}
\hline Final composition & Weight percentage \\
\hline Na-PMAA polymer & $0.67 \%$ \\
Sodium acetate & $56.67 \%$ \\
Water & $40.63 \%$ \\
$\mathrm{Na}_{2} \mathrm{HPO}_{4} \cdot 2 \mathrm{H}_{2} \mathrm{O}$ & $2.02 \%$
\end{tabular}

dehydration events were observed and the following compounds were sequentially identified: $\mathrm{Na}_{2} \mathrm{HPO}_{4} \cdot 8 \mathrm{H}_{2} \mathrm{O}$, $\mathrm{Na}_{2} \mathrm{HPO}_{4} \cdot 7 \mathrm{H}_{2} \mathrm{O}, \quad \mathrm{Na}_{2} \mathrm{HPO}_{4} \cdot 2 \mathrm{H}_{2} \mathrm{O}, \quad \mathrm{Na}_{2} \mathrm{HPO}_{4} \cdot \mathrm{H}_{2} \mathrm{O}$, and $\mathrm{Na}_{2}-$ $\mathrm{HPO}_{4}$. Under the conditions of a flowing nitrogen stream, $\mathrm{Na}_{2} \mathrm{HPO}_{4} \cdot 2 \mathrm{H}_{2} \mathrm{O}$ began to dehydrate to the monohydrate at 72 ${ }^{\circ} \mathrm{C}$, with further dehydration to the anhydrous salt at $82{ }^{\circ} \mathrm{C} .{ }^{32}$ One remaining question is why the addition of anhydrous $\mathrm{Na}_{2} \mathrm{HPO}_{4}$ to bulk samples of SAT appears to promote reliable nucleation. This is because the sparingly soluble $\mathrm{Na}_{2} \mathrm{HPO}_{4}$ recrystallises from solution as the dihydrate under certain conditions, and especially when SAT freezes, thereby explaining why nucleating behaviour can be regenerated either by reducing the temperature of sub-cooled samples to below $0{ }^{\circ} \mathrm{C}$ or adding a seed crystal of SAT in order to promote crystallisation of the entire sample. Based on these results, it seems likely that a similar thermally induced dehydration mechanism is responsible for the deactivation of $\mathrm{Na}_{4} \mathrm{P}_{2} \mathrm{O}_{7}$ when used as nucleator. Only the decahydrate and the anhydrous form are known and so dehydration of the decahydrate may be responsible for its deactivation. This is supported by the observation that the melting point of $\mathrm{Na}_{4} \mathrm{P}_{2}$ $\mathrm{O}_{7} \cdot 10 \mathrm{H}_{2} \mathrm{O}$ is reported to be in the range $69-79{ }^{\circ} \mathrm{C} .{ }^{33}$ The in situ temperature-cycling experiments also showed that no anhydrous sodium acetate was ever observed for any of the compositions containing either of the polymer additives, thereby confirming that incongruent melting was successfully prevented. The results of these studies allowed us to develop an optimum formulation based on Na-PMAA with the composition shown in Table 3.

Extended lifetime testing in a Sunamp heat battery shows that this PCM formulation performs reproducibly over $>40$ 000 cycles. Independent testing of this PCM formulation has also been conducted by the RAL Quality Association PCM and the results show no deterioration of performance over $>10000$ heating and cooling cycles according to the testing regime described in RAL-GZ $896 .^{34}$

\section{Conclusions}

This study has identified two polymer additives that when added in low concentrations can be used to reliably prevent incongruent melting of sodium acetate trihydrate (SAT) when temperature-cycled over multiple thousands of melting and freezing cycles. The polymers appear to act as crystal-habit modifiers that at sub-optimal concentrations dramatically alter the morphology of any anhydrous sodium acetate that may be formed and at higher concentrations completely suppress precipitation of anhydrous sodium acetate. In agreement with previous studies, it was found that only the following compounds were effective at reliably initiating the crystallisation of SAT at or very close to $58{ }^{\circ} \mathrm{C}$ : anhydrous $\mathrm{Na}_{2}$ $\mathrm{HPO}_{4}, \mathrm{Na}_{2} \mathrm{HPO}_{4} \cdot 7 \mathrm{H}_{2} \mathrm{O}$, anhydrous $\mathrm{Na}_{4} \mathrm{P}_{2} \mathrm{O}_{7}$, and $\mathrm{Na}_{4} \mathrm{P}_{2} \mathrm{O}_{7} \cdot 10 \mathrm{H}_{2}-$ O. It was also observed that samples of SAT containing either $\mathrm{Na}_{2} \mathrm{HPO}_{4}$ or $\mathrm{Na}_{4} \mathrm{P}_{2} \mathrm{O}_{7}$ for variable time periods at temperatures above $70{ }^{\circ} \mathrm{C}$, it was observed that nucleation was no longer reliable. When heated over the temperature range $79-87^{\circ} \mathrm{C}$, samples nucleated inconsistently on cooling, and always failed to nucleate when heated above $87^{\circ} \mathrm{C}$. In situ X-ray powder diffraction studies have demonstrated that when anhydrous $\mathrm{Na}_{2} \mathrm{HPO}_{4}$ was added to SAT, the dihydrate, $\mathrm{Na}_{2} \mathrm{HPO}_{4} \cdot 2 \mathrm{H}_{2} \mathrm{O}$, was formed and this is the active nucleator for crystallisation of SAT. On heating to $90^{\circ} \mathrm{C}$, the dihydrate formed anhydrous $\mathrm{Na}_{2}-$ $\mathrm{HPO}_{4}$ that failed to nucleate crystallisation of SAT on subsequent cooling. This set of in situ experiments therefore shows that the active nucleator for SAT is actually the dihydrate, and that the mechanism of thermally induced deactivation is dehydration in solution to form anhydrous $\mathrm{Na}_{2}$ $\mathrm{HPO}_{4}$. Based on these studies, new formulations of SAT have been developed that demonstrate consistent and reliable performance (over $>40000$ heating/cooling cycles) as PCMs for heat-storage applications. In particular, elucidation of the mechanism of the thermal deactivation of the nucleator has informed subsequent design of heat-storage systems, thereby establishing a maximum operating temperature for the PCM. The demonstration that low concentrations of polymer additives, which act as crystal-habit modifiers, are able to suppress incongruent melting of salt hydrates represents an important development for the field, and opens up opportunities for the potential use of other incongruently melting salt hydrates as PCMs in heat-storage applications. Future work will therefore focus on elucidating the mechanism by which these polymer additives act as crystal-habit modifiers and suppress incongruent melting.

\section{Conflicts of interest}

There are no conflicts of interest to declare.

\section{Acknowledgements}

We thank the EPSRC for a CASE Award Studentship for DEO and acknowledge the Diamond Light Source for time on Beamline I11 under Proposal CM 2060.

\section{References}

1 S. D. Sharma and K. Sagara, Int. J. Green Energy, 2005, 2, 1.

2 D. Rozanna, T. G. Chuah, A. Salmiah, T. S. Y. Choong and M. Sa'ari, Int. J. Green Energy, 2004, 1, 495.

3 A. Sharma, V. V. Tyagi, C. R. Chen and D. Buddhi, Renewable Sustainable Energy Rev., 2009, 13, 318.

4 K. K. Meisingset and F. Grønvold, J. Chem. Thermodyn., 1984, 16, 523.

5 G. A. Lane, Solar Heat Storage: Latent Heat Materials, Volume II: Technology, CRC Press, 1986. 
6 N. Araki, M. Futamura, A. Makino and H. Shibata, Int. J. Thermophys., 1995, 16, 1455.

7 H. Kimura and J. Kai, Sol. Energy, 1985, 35, 527.

8 L. F. Cabeza, G. Svensson, S. Hiebler and H. Mehling, Appl. Therm. Eng., 2003, 23, 1697.

9 T. Wada, F. Kimura and Y. Matsuo, Bull. Chem. Soc. Jpn., 1983, 56, 3827.

10 W. Kong, M. Dannemand, J.-B. Johansen, J. Fan, J. Dragsted, G. Englmair and S. Furbo, Sol. Energy, 2016, 139, 249.

11 J. Liu, C. Zhu, W. Liang, Y. Lia, H. Bai, Q. Guo and C. Wang, Sol. Energy, 2019, 193, 413.

12 M. A. Rogerson and S. S. S. Cardodo, AIChE J., 2003, 49, 505.

13 C. Liu, P. Hu, Z. Xu, X. Ma and Z. Rao, Thermochim. Acta, 2019, 674, 28.

14 Z. Wang, S. Liu, G. Ma, S. Xie, G. Du, J. Sun and Y. Jia, Int. J. Energy Res., 2017, 41, 2555.

15 W. Cui, Y. Yuan, L. Sun, X. Cao and X. Yang, Renewable Energy, 2016, 99, 1029.

16 M. Fashandi and S. N. Leung, Sol. Energy Mater. Sol. Cells, 2018, 178, 259.

17 H. Kimura, Nippon Kessho Seicho Gakkaishi, 1982, 9, 73.

18 J. Mao, X. Dong, P. Hou and H. Lian, Appl. Therm. Eng., 2017, 118, 817.

19 T. Wada and R. Yamamoto, Bull. Chem. Soc. Jpn., 1982, 55, 3603.

20 C. Rudolph, Ph.D. Thesis, TU Bergakademie Freiberg, Germany, 2002.

21 T. Wada and H. Yoneno, Bull. Chem. Soc. Jpn., 1985, 58, 919.

22 T. Wada and Y. Matsuo, Bull. Chem. Soc. Jpn., 1984, 57, 561.
23 J. Guion and M. Teisseire, Sol. Energy, 1991, 46, 97.

24 K. Saita, F. Goto, M. Ishida and H. Hamamatsu, J. Chem. Eng. Jpn., 2007, 40, 36.

25 W. J. Benton, I. R. Collins, I. M. Grimsey, G. M. Parkinson and S. A. Rodger, Faraday Discuss., 1993, 95, 281.

26 L.-Y. Hsu and C. E. Nordman, Acta Crystallogr., Sect. C: Cryst. Struct. Commun., 1983, 39, 690.

27 S. P. Thompson, J. E. Parker, J. Potter, T. P. Hill, A. Birt, T. M. Cobb, F. Yuan and C. C. Tang, Rev. Sci. Instrum., 2009, 80, 75107.

28 S. P. Thompson, J. E. Parker, J. Marchal, J. Potter, A. Birt, F. Yuan, R. D. Fearn, A. R. Lennie, S. R. Street and C. C. Tang, J. Synchrotron Radiat., 2011, 18, 637.

29 K.-T. Wei and D. L. Ward, Acta Crystallogr., Sect. B: Struct. Crystallogr. Cryst. Chem., 1977, 33, 522.

30 M. Catti, G. Ferraris and M. Franchini-Angela, Acta Crystallogr., Sect. B: Struct. Crystallogr. Cryst. Chem., 1977, 33, 3449.

31 M. Baldus, B. H. Meier, R. R. Ernst, A. P. M. Kentgens, H. Meyer zu Altenschildesche and R. Nesper, J. Am. Chem. Soc., 1995, 117, 5141.

32 A. Ghule, C. Bhongale and H. Chang, Spectrochim. Acta, Part A, 2003, 59, 1529.

33 D. H. Templeton, H. W. Ruben and A. Zalkin, J. Phys. Chem., 1990, 94, 7830.

34 Phase Change Materials Quality Assurance RAL-GZ 896 RAL, Deutsches Institut für Gütesicherung und Kennzeichnung E. V., https://www.pcm-ral.org/pdf/RAL_GZ_896_Phase_Change_ Material_Edition_March_2018.pdf. 